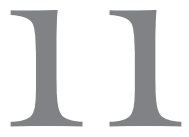

\title{
Experiencing relational depth: self-development exercises and reflections
}

\section{Mick Cooper}

Since the publication of Working at Relational Depth in Counselling and Psychotherapy by Dave Mearns and myself (Mearns and Cooper, 2005), I have developed a range of exercises to help counsellors and psychotherapists explore and develop their capacity to relate to their clients in depth. These exercises, of course, are not a 'how to' guide on making relational depth happen: by their very nature, moments of relational depth cannot be contrived. Rather, they are an invitation to explore experiences of relational depth (as 'moments'; see Chapter 1, this volume), and to consider ways in which this experiencing might be facilitated or inhibited. Although the exercises are oriented towards counsellors or psychotherapists with a background in person-centred therapy, I have found that they can also be helpful for therapists of other orientations.

For the purposes of this chapter, most of these exercises are described for readers to try out on their own, ideally in some quiet and private space. Exercise 5, however, does require a partner; and for each of the exercises, I have suggested how they might be undertaken with other people. This might be colleagues in the counselling field, such as fellow practitioners or students, as part of a supervision group, or on a training course. A version of this chapter written specifically for trainers, with additional notes on how these exercises might be delivered in a group format, is available at pure.strath.ac.uk/portal/.

Each of these exercises has the capacity to evoke powerful emotions. It is important, therefore, to only undertake the exercises that you feel happy to try out, and if you do them on your own, do make sure there is someone available for you to debrief with, should the need arise. 


\section{Reviewing relational connections}

\section{Aim}

To raise your awareness of how everyday relational interactions may affect your mood.

\section{The exercise}

1. Reflect on the relational encounters that you have had this morning. This may include:

- 'Real' others: for example your partner, the cat

- 'Imaginary' others: for example someone you were having a conversation with in your imagination.

2. Ask yourself:

- What was the quality of the connection like with that person? For example good, bad, indifferent

- How did that impact on you? For example depressed me, energized me.

\section{Dyad/group variation}

Pair up with someone and take 10 minutes each to explore the questions above.

\section{Reflections}

Through this simple exercise, people generally notice how much of an impact relational encounters can have on their feelings and way of being. An argument with their partner, for example, sets them off on a bad mood; a cuddle with their son that morning gives them a warm glow. This highlights how our experiencing is not closed or cut off from others, but intrinsically connected to other people in the world. As Heidegger (1962) and other intersubjective thinkers have put it, our being is always a 'being-in-relationship'.

\section{Experiencing relational depth}

\section{Aim}

To help you develop an awareness of the experience of relational depth.

\section{The exercise}

Explore the following question: 'If you were experiencing an in-depth sense of connection with another person right now, that is, experiencing relational depth, how would you know it? For example:

- What would you be feeling in yourself? For example 'exhilarated', 'vulnerable'

- What would your experience of the other person be like? For example 'They would seem very open' 
- How would the relationship be experienced? For example 'A real sense of cohesion'

- What would the atmosphere be like? For example 'A sense that something magical is taking place'.

In reflecting on this, you may find it helpful to think about times in which you have experienced a deep sense of connection with another person (not necessarily within a therapeutic relationship) in your life. What was it like?

As an additional/alternative exercise, try expressing your experience of relational depth through drawing, painting or some other creative medium, such as poetry.

Have a look at the review of research findings on the experience of relational depth (Chapter 5, this volume). Do your own experiences match?

\section{Dyad/group variation}

Take 15 minutes with a partner, and ask yourselves: 'If we were experiencing an in-depth sense of connection with each other right now, how would we know?'

\section{Reflections}

I have facilitated this exercise many times in groups, and I am still struck by how frequently the same words or phrases come up to describe this experience of in-depth relating; for example, mutuality, synchronicity, trust, stillness, openness, safety, warmth, equality, no need for words, aliveness, sense of time standing still, feeling in your stomach, a tingling all over. Also, some great idiosyncratic descriptions always come up; for example, soupiness, walking on the edge of falling in love, a feeling of holding each other's hearts, reading each other without words being spoken. For me, it really helps to affirm my belief that, although it is by no means clear what moments of relational depth are, there is something 'there', something that many of us seem to experience, and something that is worthy of further exploration.

\section{A life without relational depth}

The basic assumption underlying this exercise is that, for many of us, good interpersonal relationships are central to our psychological wellbeing (see Means and Cooper, 2005, Ch. 2), and that interpersonal disconnections, as well as intrapersonal ones, can be a primary source of psychological distress.

\section{Aims}

1. To help you explore the relationship between relational depth and psychological wellbeing. 
2. To help you develop your ability to empathize with clients who may be experiencing isolation and a lack of in-depth relating in their lives.

\section{The exercise}

In a quiet space, sit or lie comfortably, and close your eyes. Imagine what it would be like to live a life without any in-depth connections to others. How would it feel? What would your life be like? In asking yourself these questions, you may find it useful to think about times in your life where you have experienced such an absence.

As with the previous exercise, you may find it useful to express your perception/experiencing of a life without relational depth through some creative medium, such as drawing.

As a follow-up exercise, ask yourself this question: How much do you agree or disagree with the statement: 'Chronic disconnection from others is the primary source of psychological distress' (Jordan et al., 2004). Consider this particularly in relation to clients you are working/have worked with and yourself.

You may also find it interesting to ask yourself: How is it that relational disconnections might emerge in the first place, particularly if people have a natural propensity to relatedness? (See Mearns and Cooper, 2005, Ch. 1.)

\section{Dyad/group variation}

In a group context, after conducting the visualization, you can share your experiences/perceptions with a partner, and then go on to discuss the questions above.

\section{Reflections}

Doing this exercise for myself, it always strikes me how painful it is to think about a life without connection. I remember a time in my early twenties, travelling through Greece, when I had not had any meaningful connection with anyone for a few days. I was aching with pain - a real deep, desperate yearning - and was approaching anyone who looked like they might talk a bit of English to try and establish some connection. So a life that is consistently like that, for me, is almost too awful to contemplate, and many people who do this exercise seem to come to the same conclusion. But I do think that, for some of our clients, that is the reality of their lives - a deep, painful, aching sense of isolation and disconnection - and as therapists, who may be used to fairly deep connections with others in our lives, it might be easy to forget that not everyone exists in this way.

Interestingly, when doing this exercise, some people may say that they can also see the positive side of a life without any connections: a sense of freedom, liberation, not being tied down to anyone. And, indeed, in a small number of 
instances, participants have said that this is pretty much what their current life is like, and that this is a personal choice, which feels okay. Obviously, it is important to value such contributions, and not to work from the assumption that relational depth is, de facto, a good thing. I think Martin Buber (1958), the great relational philosopher, puts this very well when he says that we will always have times when we experience the world in relatively disconnected, I-It ways. Indeed, these times can be very important and necessary. But when that is all we have, when there is a total absence of I-Thou moments of connectedness, then we can really struggle.

When I have facilitated this exercise with person-centred therapists, subsequent discussions tend to pivot around the question of whether psychological distress is primarily caused by disconnections with others, or by disconnections with one's own self. Almost invariably, we come to the conclusion that the two are so interlinked that either, or both, could be the starting point for psychological difficulties. I do tend to argue, however, that in classical personcentred developmental theory (for example Rogers, 1951, 1959), the emphasis is very much on intrapersonal splitting - between the self-experience and the self-concept - with very little said, explicitly, about the potential damage that a lack of interpersonal relating can do. Indeed, in classical person-centred theory, the role of the Other is primarily as the one who dismupts our natural, organismic growth (through conditional positive regard); and this contrasts with other relational models of development (for example Bowlby, 1979), which speak much more explicitly about a human need for others. Another way I have put this is to say that, from a relational perspective, there is something that we need for our wellbeing that only others can provide - what Hycner (1991, p. 61) has termed a 'deep soul-nourishment'. So, from this perspective, it may not be enough for us just to like ourselves, we need other people to like us: positive regard is not a secondary, learned need (Rogers, 1959), but a fundamental ingredient of a satisfying and meaningful existence. For me, Martin Buber (1988, p. 61) puts this beautifully, when he writes:

The human person needs confirmation because man as man needs it ... Sent forth from the natural domain of species into the hazard of the solitary category, surrounded by the air of chaos which came into being with him, secretly and bashfully he watches for a Yes which allows him to be and which can come to him only from one human person to another. It is from one man to another that the heavenly bread of self-being is passed.

This can, then, lead on to a discussion of how person-centred practice, from a relational depth perspective, might differ from a more classical approach (for example Merry, 2004; Rogers, 1942). How I tend to think about this is as follows: if we assume that the principal source of psychological distress is intrapersonal disconnection, as a consequence of the existence of conditional positive regard (Rogers, 1959), then it makes absolute sense that the most 
healing thing we can do is to provide our clients with an unconditionally positively regarding context, in which they can begin to 'put themselves back together again'. However, if psychological distress is also understood in terms of real, in-the-world splits between self and others, then establishing a specific, person-to-person connection also becomes a key element of helping some clients back into health and wellbeing. This is a subtle distinction but, for me, it is like the difference between providing a 'crucible' for clients to do their work, versus providing a more immediate, person-to-person encounter (see Figure 11.1).

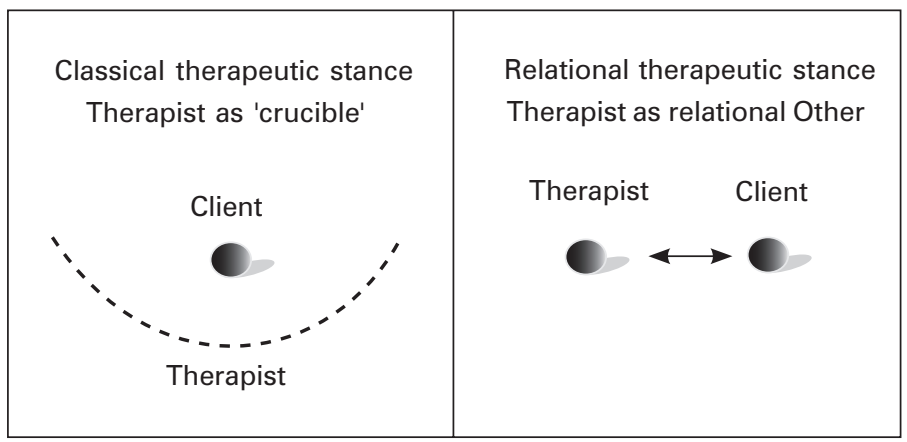

Figure 11.1 Classical and relational therapeutic stances

What does this mean in terms of actual practice? For me, a relational way of being person-centred, in contrast to a more classical one, may mean:

- bringing more of my own experiences or perceptions into the encounter with the client

- being less of a mirror and more of an actual other with different views and beliefs

- moving away from a therapy that is wholly oriented around an 'empathic understanding response process' (Freire, 2007) towards one that might involve a variety of different forms of engagement - asking questions, probing, giving input, maybe even offering advice - depending on what particular clients seem to want at particular times

- moving beyond a neutral, nonjudgemental 'acceptance' of the client to a more active, intentional prizing of their being-in-the-world: not just a 'however they experience the world is fine', but a deep relational affirmation of their being in all its uniqueness (see Chapter 2, this volume)

- being willing to share with a client my genuine care or concerns for them (see Chapter 2, this volume). 
But are these differences really meaningful? It is at this point in workshops that I often find myself in lively disagreement with person-centred participants. Some feel that I am caricaturing the classical person-centred approach, and that they would do all these things anyway. Some simply cannot see what the distinction is all about. Others, though, do get a sense that there is a subtle shift of emphasis here; and that while it is by no means an either/or dichotomy, there is some spectrum of person-centred practice that ranges from a more 'holding', nondirective stance to a more active, dialogical one - and that different clients do best with different emphases at different points in time. Indeed, I know for myself that since studying and writing about relational ideas, I have become a different kind of therapist: more 'just myself' with my clients, more relaxed and informal, less 'precious', more willing to just 'get stuck in' with a client and do whatever might seem helpful at that particular point in time.

\section{Strategies of disconnection}

This exercise is a way into exploring the question of how we, as therapists, might be able to deepen our relationship with our clients. The theory behind this exercise comes from the work of Judith Jordan and colleagues (Jordan et al., 2004), mentioned above. It starts with a paradox: evidence from the child and developmental psychology field (see Mearns and Cooper, 2005, Ch. 1) makes it is clear that human beings want, and are able, to engage deeply with others from the first moments of life. But then, how is it possible that so many of us can become so chronically disconnected from others, with all the psychological difficulties that can follow? Jordan et al. answer this paradox by suggesting that we may develop 'chronic strategies of disconnection'. These are ways that we may have developed of protecting ourselves from hurts in early close relationships that then become fixed and sedimented, such that we carry on protecting ourselves from intimacy even when, as an adult, that relational depth may actually be very healing. A young girl, for instance, is teased by her mother for wanting closeness and intimacy; so she learns to withdraw from connection, perhaps by removing herself physically, perhaps by detaching herself in her own head. And, as an adult, she continues to withdraw physically or psychologically from the possibility of closeness with others, even when those encounters could provide her with exactly the deep soul nourishment that she so desperately craves.

So this exercise invites you to think about your own chronic strategies of disconnection, and it goes on from this to invite you to think about whether any of these strategies may be relevant in your therapeutic work. For, without doubt, we will bring into the therapeutic work who we are, and if we have ways of disconnecting from relationships in our everyday lives, there is a strong possibility that these may also turn up in our clinical work. 
144

A personal example: as a child, if I got hurt or upset by my family, I would threaten to leave home and go sit outside the front door of our flat for what seemed like ages (although probably only five minutes or so), before boredom or hunger would set in and take me back inside. As an adult, I can still tend to deal with personal hurt by withdrawing, and by walking away from situations when, in fact, I would often be better off addressing the problem and trying to re-establish connection. And I can also see how this is sometimes played out in my therapeutic practice. For instance, if a client tells me that they want to end therapy, I am sometimes very quick to agree with them that it is the best thing to do, and that it is 'really fine' with me, rather than inviting them to spend a bit more time exploring their feelings. Essentially, what seems to happen here is that I feel a bit rejected or hurt, and I deal with it by quickly withdrawing from the situation, rather than giving things a bit more time to be worked through, and for a connection to be re-established.

\section{Aim}

To help you develop an awareness of what might get in the way of you relating more deeply with others, and particularly your clients.

\section{The exercise}

1. Reflect on this question: 'What are your chronic strategies of disconnection?' That is, what are the ways that you, in your life, pull away from deeper relating with others, when to remain in connection might actually be more rewarding? For example withdraw mentally, use humour, avoid physical closeness, become compliant, stop listening, become very formal.

2. Reflect on this question: 'To what extent might these strategies of disconnection also be present in your therapeutic work?' For example, if you use humour to distance yourself from people in your everyday life, are there also times when you do this with your clients? If none of these strategies are present, what might be other ways in which you disconnect from clients in the therapeutic encounter?

\section{Dyad/group variation}

With a partner, take 10 minutes each to explore your general strategies of disconnection (question 1, above). Once you have both done this, explore together how manifested these strategies might be in your therapeutic work.

\section{Reflections}

It is important to emphasize that this exercise encourages you to consider chronic strategies of disconnection: things that you do, systematically, to pull away from deeper relating to others, and which are potentially redundant or unhelpful. So, it is not about things that you do to keep yourself safe from 
destructive or harmful relationships, but ingrained patterns that may get in the way of you obtaining deeper, more satisfying levels of relating.

In my experience, some people who do this exercise are really struck by how commonly their chronic strategies of disconnection are carried over into the therapeutic relationship, while others find very few parallels at all. Of course, both answers are totally appropriate.

From data that Rosanne Knox and myself are currently analysing, it seems that the five most common strategies of disconnection that therapists (mainly person-centred practitioners and trainees) use in their lives are as follows (in approximately descending order):

- Mental withdrawal: for example 'Thinking about something else at the same time as talking to someone'

- Physical avoidance: for example 'Send emails instead of speaking'

- Silence/quietness: for example 'Go "mute" for a while'

- Humour: for example 'Make a joke'

- Aggressiveness: for example 'Express irritation/anger/frustration'.

However, the five strategies of disconnection that were rated as being most present in their therapeutic work were as follows (again, in roughly descending order of relevance):

- Rescuing: for example 'Doing over helpful'

- Other focus: for example 'Being a good listener but not sharing'

- Hiding/invisibility: for example 'Quietly disappearing'

- Intellectualization: for example 'Stay in the head rather than go to the feelings'

- Conflict avoidance: for example Avoid challenging others'.

It would be interesting to see if therapists from other orientations also tended to disconnect from their clients in these ways.

On the basis of this research, Rosanne Knox has developed a short questionnaire that can be used by people to reflect on their chronic strategies of disconnection (see Appendix at end of chapter). The instrument is yet to be validated and finalized, but the version presented here may still be a useful tool for helping to think about your own strategies of disconnection: both outside and inside the therapeutic encounter.

\section{Developing embodied empathy}

This exercise does need to be conducted with a partner. It is based on the concept of 'embodied empathy', a term I have used (Cooper, 2001; Mearns and Cooper, 2005) to describe a form of interpersonal engagement that goes 
beyond a purely cognitive, or even affective, understanding of someone's world towards a full-bodied resonance with their being. I might experience, for example, a tightness in my stomach as a client talks about a particularly frightening situation, or a pressure on the top of my head as they describe the stresses they are under. As with relational depth, embodied empathy does not seem to be something that I can make happen, but it may be something that therapists can be more or less open to and, as the research would suggest (see Chapter 5, this volume), it seems to be an important ingredient of a relationally deep encounter.

\section{Aims}

1. To help you develop your capacity to empathize with your clients in an embodied way.

2. To help you appreciate the value of, and develop a trust in, your own embodied experiences in relation to clients.

3. To help you become more relaxed and spontaneous in your practice.

\section{The exercise}

1. With a partner, decide who will be the talker and who will be the listener.

2. The talker should talk for around 10 minutes about an issue of current concern that has some emotional content, that is, there is some emotion there, but not so much that it needs a more extended period of talking through.

3. The listener should do the following:

- First, sit yourself as comfortably as possible. Let yourself be as relaxed as you can, and don't worry about anything you have been taught about how to sit or look when you are counselling.

- As the talker starts to talk, try and let yourself 'breathe in' what they are saying. Give yourself time to resonate, at a physical level, with what the talker is expressing. Just notice what you are feeling physically.

- Try not to worry about what you are going to say. In fact, try not to say too much at all, aside from brief interjections like 'mm', 'aha' and so on.

- The only other time you should respond at length is if you feel some physical sensation in response to what the talker is saying. For example, you might experience an aching in your shoulders or a sense of numbness throughout your body, and you should share this with the talker, for instance: 'As you describe that argument, I can feel a real tightness in my chest.' Don't worry if it seems totally out of place, just give it a go.

- You may not feel any physical resonance for the whole period, and that is fine. Just don't say too much.

4. Swap roles and repeat.

5. Take 10 minutes or so to discuss this experience:

- How did it feel to listen in this way?

- How did it feel to be listened to in this way? 
- To what extent did the physical sensations that you reflected match what the client was experiencing?

\section{Reflections}

Some people seem to find this exercise really interesting and helpful, while others, quite honestly, don't. It often seems to be most helpful for individuals in the initial stages of counsellor training, and particularly where they are experiencing a pressure to work in a relatively formulaic, unspontaneous way, for example 'sit upright', 'reflect', 'don't ask questions'; or where they are really worried about how they 'should' respond to their 'clients'. Such participants have said that they find this exercise really liberating, helping them feel much more enthusiastic about their work as counsellors, or counselling skills practitioners. On the other hand, some trainees, as well as some more experienced practitioners, find the practice in this exercise quite restrictive and unnatural. It is important to emphasize, therefore, that this exercise is just about trying something out, and is not a mandate on how you should practise from here onwards.

When this exercise does work for people, they can be really surprised at how accurately their own bodily experiences mirror those of the clients. This can help them to trust, more fully, their own felt reactions to clients, and to draw on them more fully in their therapeutic work, thus deepening their level of relating. My favourite feedback, however, was from a Danish psychologist who, at the end of a relational workshop day, wanted to say how much she had liked this embodiment exercise. Unfortunately, she didn't get her English quite right and so said to me, in front of a large group of her colleagues, 'I very much like your body.' The fact that she had been offering psychoanalytic interpretations throughout the day made it even funnier.

\section{Interpersonal perception: factors that facilitate, and inhibit, connection}

This exercise is probably best conducted in a group context, although it has the potential to be quite challenging - as well as very rewarding. In my experience, it tends to be most helpful for groups of participants who have had previous interactions with each other, for example students on the same diploma training course or colleagues in a local counselling network, and where there is an opportunity for ongoing processing of what emerges from it. It is essential that participants in this exercise, if done in a group, have had some basic training in therapeutic or personal development work, such that they are able to hear feedback in a nondefensive way, and to share it in a way that is 'owned' and noncritical.

The exercise is based on the premise that it is not just the things we intentionally do, whether consciously or 'unconsciously', that get in the way of us 
connecting with others and our clients (as in our chronic strategies of disconnection, above). Also, there may be things about us that are simply there, perhaps just by chance, that make others more wary of connecting with us. For example, over the years, I have come to realize that my physical presence - as a fairly broad man, with dark features and a fairly deep voice - can lead people to feel quite intimidated, even when, actually, I might be feeling quite frightened or vulnerable myself. In fact, I have even had the experience of specifically saying to people - fellow trainees in a personal development group, colleagues - that I am feeling scared and vulnerable, and them refusing to believe it because of something in how I am coming across. So, in developing our capacity to connect with others, it may be quite important to have a sense of how others experience us (our metaperceptions; see Cooper, 2005, 2009), such that we can try and address any aspects of ourselves that inhibit contact. Of course, this does not mean that we should change who we are but simply being aware of it or perhaps finding ways to compensate for it may be of value; for example, I might try to communicate my vulnerabilities more fully.

\section{Aims}

1. To help you develop your awareness of aspects of yourself that might make others, including clients, wary of making contact with you.

2. To help you develop your awareness of aspects of yourself that might make others, including clients, drawn towards making contact with you.

\section{The exercise}

1. Reflect on, and write down, those characteristics of you that might make people drawn towards connecting with you, and those that might make them wary of connecting with you.

2. You may then want to check this out with someone who knows you, such as a colleague in the counselling field or a fellow trainee, to see if they actually do experience you in this way, or whether there are other things that actually draw them towards, and make them wary of, connecting with you. Try to find someone who you can trust to respond in a sensitive way, but also who will be open enough to articulate anything that might make them more wary of connecting with you (see guidelines for feedback, below).

\section{Group variation}

1. Form into groups of four. As far as possible, try to go into groups with people you have had some prior interaction with, but not people you know extremely well.

2. On a piece of A4 paper (landscape orientation), create a three by five grid (that is, draw two horizontal lines, and four vertical lines, equally spaced apart) (see Figure 11.2). In the top row of the second to fifth column, have the name of each of the other group members. In the left-hand column of the second row, write: 'Perceptions of this person that/make me want to 
connect with them'. In the left-hand column of the third row, write: 'Perceptions of this person that make me wary of connecting with them'.

3. Now, take 10 minutes, and for each member of your group write down, in the relevant parts of the grid, what makes you drawn to, and wary of, connecting with them. In doing so, bear the following in mind:

- Be clear that what you are writing down is your experience/perception of this person, and not some objective assessment. So, it is not about telling someone what their personality or character is 'really' like, but about 'owning' your personal perception or experience of them, with an acknowledgement that someone else might experience them in a very different way.

- Find a good balance between being honest and being sensitive. You will be asked to share these perceptions with the other person (although, of course, you don't have to), and given the limited time frame for the exercise, it is important that you don't open up a whole set of issues that cannot be dealt with in the given time span. On the other hand, the more honest you are with someone, the more useful this is likely to be.

- If you have had no contact with someone, write down your first impressions.

4. Now, pair up with one of the members of your group, and one of the pair should take 10 minutes to share with their partner, and discuss, the perceptions of them that make them drawn to, and wary of, connection with them. Now take 10 minutes to do this the other way round.

5. Now pair up with another member of your group and repeat Step 4 (this should take 20 minutes per pair). Repeat again with the final member of your group.

6. In a large or small group, discuss this exercise (maybe 30 minutes or so). What did you learn about yourself?

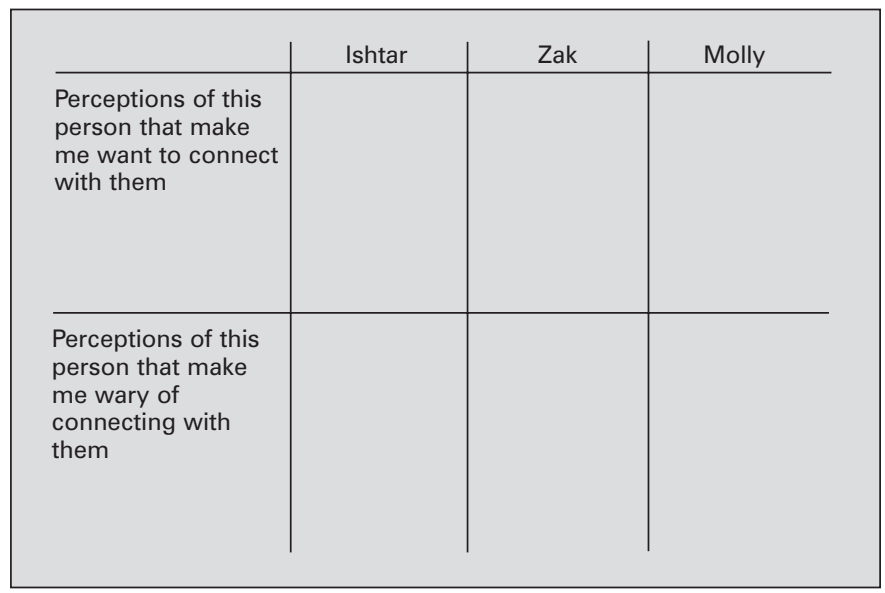

Figure 11.2 Example grid for interpersonal exercise 
This exercise can also be undertaken in threes. Just adjust the grid accordingly, that is, three columns instead of four, and take 10 minutes or so, in turn, for each person to receive feedback from their partner(s).

\section{Reflections}

When this exercise is conducted in a group or with pairs giving feedback, it is essential to remember that the task is to write down how you perceive or experience others, and not to be making judgements or assessments of what the other person is actually like. When I ran this exercise with a group of Greek therapists, one of the women exclaimed: 'But how can I tell someone that they are an idiot.' I re-emphasized to her that the exercise was about really owning one's perceptions and experiences, and not making judgements about someone else. 'Oh,' she responded, 'so I should tell them that I feel they are an idiot.'

Interestingly, the kinds of perceptions that people have of others that make them wary of contact are often things that, on the surface, might seem quite positive; for example 'clever', 'knowledgeable', 'beautiful', 'experienced' or 'confident'. Sometimes, though, it seems that these perceptions can leave a person feeling intimidated or inferior. Participants also commonly state that they feel wary of contact with another person because they are worried that that person will judge them or think they are 'silly'; or because they experience someone as very open, honest and direct. On the other hand, the perception of another person as 'withdrawn', 'shy' or 'nervous' can also lead to a wariness about contact. Two physical features that come up quite often as making people wary of contact are someone being tall, and wearing glasses. 'Male' also seems to come up a lot, as does age differences, although these factors might be particularly related to a counselling context. Interestingly, too, participants often note that the features that make them wary of contact with someone are also the features that make them drawn towards contact, for example someone's perceived intelligence or their attractiveness.

\section{Conclusion}

Of course, the above exercises are just a few of the ways in which the experience of relational depth can be explored. They do, however, provide the basis for a fairly substantive exploration of the phenomenon, and one that has proved relatively engaging and informative for participants over the years. For readers who might hope to come away from these exercises knowing how to 'create' relational depth with their clients, they will prove disappointing; but as a few small steps on the journey towards a greater understanding of - and capacity to engage in - in-depth relationships, they have the potential to be some useful stimuli. 


\section{Appendix Chronic strategies of disconnection v.1}

Chronic strategies of disconnection are patterns of behaviour that people develop to protect themselves from hurt or anxiety in close relationships, but which may now be redundant: that is, they tend to do them automatically, when it may, in fact, be more beneficial for them to stay in closer connection with another person.

Reflecting on your own experience of close relationships as an adult and times in which you feel hurt or anxious, to what extent do you tend to use the following strategies to disconnect from others (when you might be better off staying in connection)?

\begin{tabular}{|c|c|c|c|c|}
\hline & Not at all & A little & Moderately & A lot \\
\hline Immersing yourself in activities, like watching TV & 0 & 1 & 2 & 3 \\
\hline Keeping busy & 0 & 1 & 2 & 3 \\
\hline Distracting yourself & 0 & 1 & 2 & 3 \\
\hline Talking a lot & 0 & 1 & 2 & 3 \\
\hline Being aggressive to, or attacking, the other person & 0 & 1 & 2 & 3 \\
\hline Being aloof or feeling superior & 0 & 1 & 2 & 3 \\
\hline Blaming the other & 0 & 1 & 2 & 3 \\
\hline Criticizing or judging the other & 0 & 1 & 2 & 3 \\
\hline Being cold, prickly or standoffish & 0 & 1 & 2 & 3 \\
\hline Being defensive & 0 & 1 & 2 & 3 \\
\hline Being controlling & 0 & 1 & 2 & 3 \\
\hline Pushing the other person away & 0 & 1 & 2 & 3 \\
\hline Being dishonest with the other person/putting up a façade & 0 & 1 & 2 & 3 \\
\hline Feigning disinterest/pretending that you don't really care & 0 & 1 & 2 & 3 \\
\hline Being formal or overly polite & 0 & 1 & 2 & 3 \\
\hline Keeping things at a superficial, surface level & 0 & 1 & 2 & 3 \\
\hline Using humour & 0 & 1 & 2 & 3 \\
\hline Avoiding communication with the other person & 0 & 1 & 2 & 3 \\
\hline Isolating yourself physically, not seeing people & 0 & 1 & 2 & 3 \\
\hline Physically withdrawing from, or avoiding, the other person & 0 & 1 & 2 & 3 \\
\hline Drugs and alcohol & 0 & 1 & 2 & 3 \\
\hline Daydreaming & 0 & 1 & 2 & 3 \\
\hline Withdrawing emotionally & 0 & 1 & 2 & 3 \\
\hline Rationalizing or overintellectualizing & 0 & 1 & 2 & 3 \\
\hline Mentally shutting down/'going into your head' & 0 & 1 & 2 & 3 \\
\hline Self-soothing/imagining a 'safe place' & 0 & 1 & 2 & 3 \\
\hline Tiredness or going to sleep & 0 & 1 & 2 & 3 \\
\hline Avoiding conflict & 0 & 1 & 2 & 3 \\
\hline Being compliant, appeasing & 0 & 1 & 2 & 3 \\
\hline Passivity/being non-responsive & 0 & 1 & 2 & 3 \\
\hline Not expressing your wants & 0 & 1 & 2 & 3 \\
\hline Being closed in your body language & 0 & 1 & 2 & 3 \\
\hline Changing the subject & 0 & 1 & 2 & 3 \\
\hline Avoiding eye contact & 0 & 1 & 2 & 3 \\
\hline Not listening & 0 & 1 & 2 & 3 \\
\hline Becoming quiet or silent & 0 & 1 & 2 & 3 \\
\hline Focusing attention on the other person & 0 & 1 & 2 & 3 \\
\hline Being overly helpful and caring for the other person & 0 & 1 & 2 & 3 \\
\hline Being independent & 0 & 1 & 2 & 3 \\
\hline Trying to make yourself invisible & 0 & 1 & 2 & 3 \\
\hline Playing things very safe, not taking any risks & 0 & 1 & 2 & 3 \\
\hline Criticizing yourself & 0 & 1 & 2 & 3 \\
\hline Feeling sorry for yourself/'playing the victim' & 0 & 1 & 2 & 3 \\
\hline
\end{tabular}




\section{References}

Bowlby, J. (1979) The Making and Breaking of Affectional Bonds. London: Routledge. Buber, M. (1958) I and Thou (trans. R.G. Smith) (2nd edn). Edinburgh: T \& T Clark. Buber, M. (1988) The Knowledge of Man: Selected Essays (trans. M. Friedman and R.G. Smith). Atlantic Highlands, NJ: Humanities Press International.

Cooper, M. (2001) Embodied empathy. In S. Haugh and T. Merry (eds) Empathy (pp. 218-29). Ross-on-Wye: PCCS Books.

Cooper, M. (2005) The inter-experiential field: Perceptions and metaperceptions in person-centered and experiential psychotherapy and counseling. Person-Centered and Experiential Psychotherapies, 4(1), 54-68.

Cooper, M. (2009) Interpersonal perceptions and metaperceptions: Psychotherapeutic practice in the inter-experiential realm. Journal of Humanistic Psychology, 49(1), $85-99$.

Freire, E. (2007) Empathy. In M. Cooper, P.F. Schmid, M. O’Hara and G. Wyatt (eds) The Handbook of Person-Centred Psychotherapy and Counselling (pp. 194-204). Basingstoke: Palgrave Macmillan.

Heidegger, M. (1962) Being and Time (trans. J. Macquarrie and E. Robinson). Oxford: Blackwell.

Hycner, R. (1991) Between Person and Person: Towards a Dialogical Psychotherapy. Highland, NY: Gestalt Journal Press.

Jordan, J.V., Walker, M. and Hartling, L.M. (eds) (2004) The Complexity of Connection: Writing from the Stone Center's Jean Baker Miller Training Institute. New York: Guilford Press.

Mearns, D. and Cooper, M. (2005) Working at Relational Depth in Counselling and Psychotherapy. London: Sage.

Merry, T. (2004) Classical client-centred therapy. In P. Sanders (ed.) The Tribes of the Person-Centred Nation: An Introduction to the Schools of Therapy Related to the PersonCentred Approach (pp. 21-44). Ross-on-Wye: PCCS Books.

Rogers, C.R. (1942) Counselling and Psychotherapy: Newer Concepts in Practice. Boston: Houghton Mifflin.

Rogers, C.R. (1951) Client-Centered Therapy. Boston: Houghton Mifflin.

Rogers, C.R. (1959) A theory of therapy, personality and interpersonal relationships as developed in the client-centered framework. In S. Koch (ed.) Psychology: A Study of Science (pp. 184-256). New York: McGraw-Hill. 